\title{
Dual-Band Antenna/AMC Combination for RFID
}

\author{
M. E. de Cos and F. Las-Heras \\ Area de Teoría de la Señal y Comunicaciones, Departamento de Ingeniería Eléctrica, Universidad de Oviedo, \\ Edificio Polivalente, Modulo 8, Campus Universitario de Gijón, Asturias, 33203 Gijón, Spain
}

Correspondence should be addressed to M. E. de Cos, medecos@tsc.uniovi.es

Received 27 February 2012; Accepted 18 May 2012

Academic Editor: Leena Ukkonen

Copyright ( $) 2012$ M. E. de Cos and F. Las-Heras. This is an open access article distributed under the Creative Commons Attribution License, which permits unrestricted use, distribution, and reproduction in any medium, provided the original work is properly cited.

\begin{abstract}
A novel antenna/Artificial Magnetic Conductor (AMC) combination usable in dual-band Radio Frequency Identification (RFID) tags over metallic objects is presented. A compact and low thickness prototype is manufactured and characterized in terms of return loss and radiation properties in an anechoic chamber both alone and on a metallic plate. The performance exhibited by the presented antenna/AMC prototype is proper for RFID tags on both metallic and nonmetallic objects.
\end{abstract}

\section{Introduction}

In Radio Frequency Identification (RFID) systems, it would be desirable that the tagged objects do not have influence on the tag antenna performance. However, on the one hand if the object surface is made of a dielectric material, then the readable range is decreased due to frequency shift of the resonance frequency. On the other hand, antennas placed nearby metallic objects suffer from performance degradation. In passive RFID systems, this fact causes important problems and it hinders their global deployment [13]. Metallic objects seriously degrade the input impedance matching, bandwidth, radiation efficiency, and readable range of the tag antenna $[4,5]$. The electromagnetic wave is greatly reflected by a conductor surface yielding a significant reduction of operating distance in RFID tags applications or total antenna malfunctioning. The negative effects increase at higher frequencies and so RFID operation in the Super High Frequency (SHF) band with tags attached to metallic objects presents an even more critical problem to be overcome.

In addition, another important question in RFID tags usable with people and wearable antennas [6-8] is the backward radiation to the human body which should be reduced as much as possible.

Different approaches have been proposed aiming to solve antennas on metals problems: patch antennas (already including a metallic ground plane) with the drawback of narrow bandwidth, new antenna designs like Planar Inverted
F Antennas (PIFAs) with the inconvenience of shorting planes not proper for flexible devices or tags, and the use of ferroelectric materials to insulate the antenna from metal, which is rather expensive.

A novel solution is proposed in this contribution combining a simple broadband antenna as a coplanar waveguide(CPW-) fed bow-tie [9-11] with a compact dual-band Artificial Magnetic Conductor (AMC) [12] without vias. Through this combination, a dual-band compact low-cost antenna proper to be used on both dielectric and metallic objects and with reduced backward radiation [13] is obtained.

The paper is organized as follows: firstly, Section 2 describes the design of a CPW-fed bow-tie antenna for operation at $5.8 \mathrm{GHz}$. Then, Section 3 shows the design of a dual-band AMC resonating at $2.48 \mathrm{GHz}$ and $5.8 \mathrm{GHz}$ to be combined with the antenna, aiming to obtain a dual-band antenna and to insulate the antenna from metallic objects. Section 4 explains the characterization of the manufactured prototypes in terms of return loss and radiation patterns. Finally some conclusions are described in Section 5.

\section{Antenna Design}

Figure 1 shows the geometry of the proposed CPW-fed bowtie antenna suitable for operating at $5.8 \mathrm{GHz}$. Double slot bow-tie geometry has been chosen as it exhibits wider bandwidth and smaller size than simple bow-tie. The antenna is 


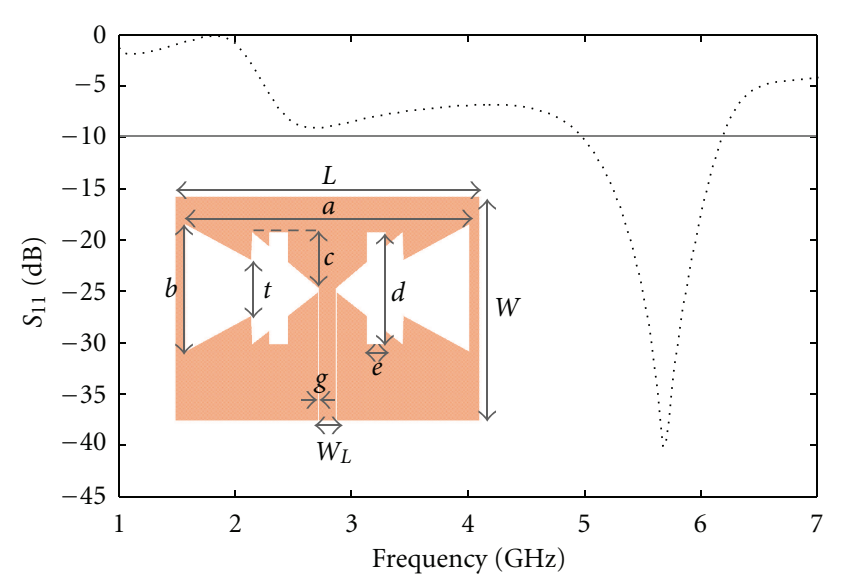

… Bow-tie (simulation)

Figure 1: Top-view of the CPW-fed bow-tie antenna geometry. Simulation results for return loss of the CPW-fed bow-tie antenna.

TABLE 1: Bow-tie antenna dimensions.

\begin{tabular}{cccccccccc}
\hline \multicolumn{10}{c}{ Dimensions (mm) } \\
\hline & $W$ & $W_{L}$ & $g$ & $a$ & $b$ & $c$ & $d$ & $e$ & $t$ \\
\hline 35 & 23.8 & 2 & 0.1 & 32.8 & 13.6 & 6 & 12 & 2.16 & 6 \\
\hline
\end{tabular}

fed through a $50 \Omega \mathrm{CPW}$ line with $W l$ strip width and $g$ gap, and it is printed on ARLON $25 \mathrm{~N}$ dielectric substrate with $h=0.762 \mathrm{~mm}$ (30 mil) thickness, $\varepsilon_{r}=3.28$ relative dielectric permittivity and less than 0.0025 loss tangent. There is no metallization on the backside. The antenna design and optimization have been carried out by a set of MoM simulations with commercial software [14].

The antenna resonance frequency is given by $a$ (increasing a shifts the operating band to a lower frequency range), whereas the bandwidth and the level of the return loss at the main resonance frequency are controlled by $b$. A trade-off is necessary between parameters $c$ and $t$ as they are opposite in behavior. Increasing the value of $c$ results in a reduction of both the frequency of operation as well as the impedance matching. Finally $e$ and $d$ can be, respectively, used for a fine bandwidth and frequency adjustment. Table 1 details the optimized antenna dimensions for operation at $5.8 \mathrm{GHz}$.

From simulated return loss shown in Figure 1, it can be concluded that the operating bandwidth of the bow-tie antenna is $1.235 \mathrm{GHz}(21.26 \%)$.

\section{Dual-Band AMC Design}

An AMC is a resonating periodic structure. The resonance frequency and the AMC operation bandwidth of an AMC structure depend on the unit-cell geometry together with the dielectric substrate's relative permittivity and thickness.

Generally AMCs [15-24] are implemented by using two-dimensional periodic metallic lattices patterned on a conductor-backed dielectric surface. Recent research efforts focus on the development of low-cost AMCs easily integrable in RF, microwave, and millimeter wave circuits. Aiming

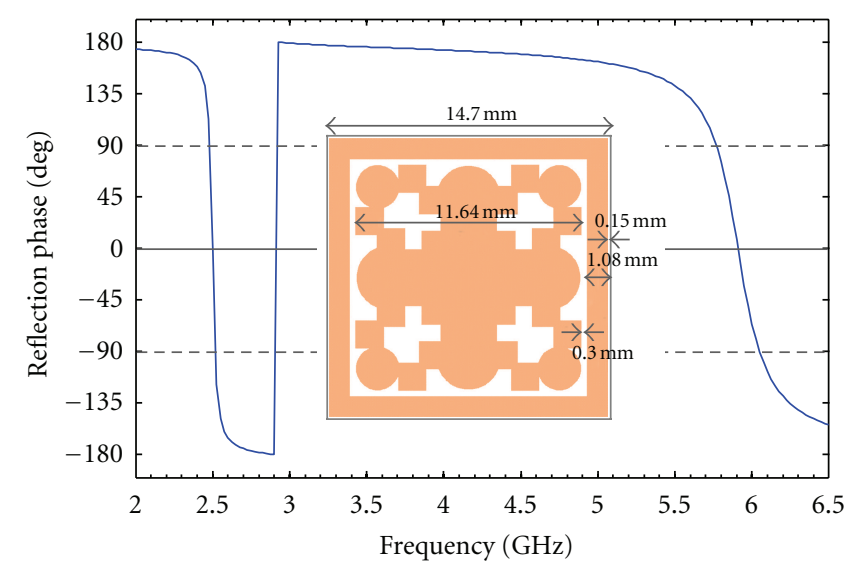

Figure 2: Dual-band AMC unit-cell geometry and dimensions. Simulated reflection coefficient phase of the AMC structure.

this, geometries without via holes [15] (in contrast to designs accomplished by patches with via holes [16]) as well as the use of a unilayer periodic Frequency Selective Surface (FSS) over a metallic ground plane (in contrast to multilayered FSSs [17]) should be considered. Both facts, removing via holes and using unilayer FSSs, reduce AMC operation bandwidth (which can be relevant depending on the application) and so an optimized unit-cell geometry design has to be carried out to overcome it.

The inherent in-phase reflection exhibited by AMCs makes possible the reduction of backward radiation for antennas placed on them and so by combining antenna and AMC in RFID tag design, low backward radiation to the human body can be obtained.

The unit-cell geometry presented in [24] is taken as reference to design a dual-band AMC. For this purpose the aforementioned geometry is surrounded by a rectangular frame (see Figure 2). The same dielectric substrate as for the antenna (ARLON 25N) is used. The unit-cell dimensions are optimized with Ansoft's HFSS [25] so that the AMC resonates at $2.48 \mathrm{GHz}$ and $5.8 \mathrm{GHz}$. Optimized dimensions are detailed in Figure 2.

Neither via holes nor multilayer substrates are required in the low-thickness dual-band AMC, simplifying implementation and reducing its cost.

From Figure 2 it can be concluded that the structure exhibits AMC performance from $2.48 \mathrm{GHz}$ to $2.51 \mathrm{GHz}$ resonating at $2.49 \mathrm{GHz}$ and from $5.77 \mathrm{GHz}$ to $6.05 \mathrm{GHz}$ resonating at $5.91 \mathrm{GHz}$. The inner geometry mainly determines the higher resonance frequency, whereas the outer square frame has more influence on the lower resonance frequency, as it can be concluded from the surface current distribution on the metallic parts of the AMC unit-cell geometry depicted in Figure 3.

The AMC performance for different polarization of the electrical incident field (under normal incidence) and under oblique incidence is very important in AMC applications for RFID tags or wearable antennas. In the case of RFID tags, the angular stability of the AMC will influence the antenna radiation performance and this will have direct impact on 


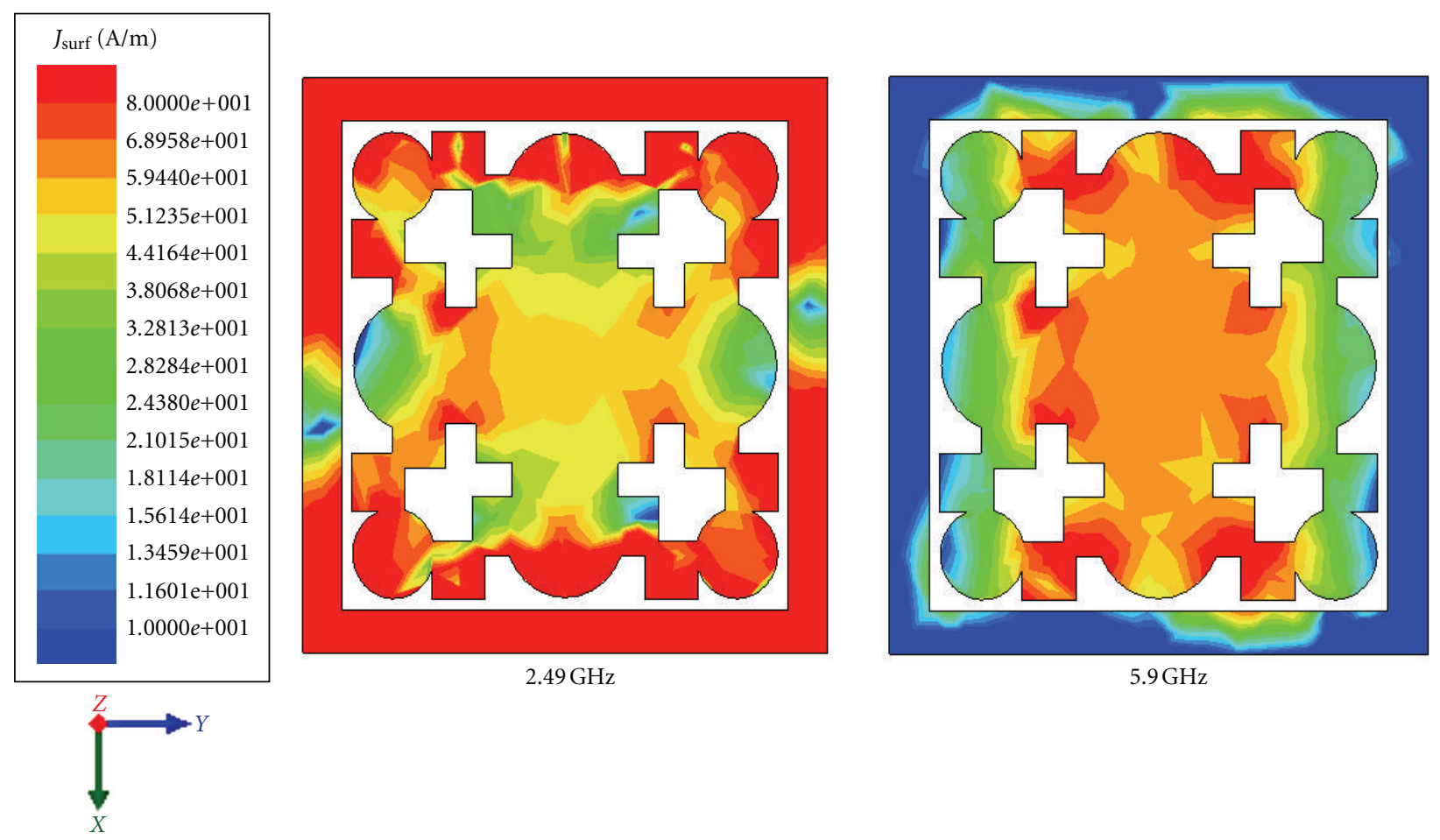

FIgURE 3: Surface currents distribution on the AMC unit-cell geometry metallic parts at $2.49 \mathrm{GHz}$ and $5.9 \mathrm{GHz}$.

the angular reading range depending on the position of the reader with respect to the tagged object. So an AMC design with as higher angular stability as possible is desirable.

The AMC has been designed so that it operates identically for any polarization of the incident field (assuming normal incidence) due to the unit-cell design geometry which exhibits four symmetry planes. With the aim of studying the angular stability margin [26] of the presented structure, the reflection coefficient phase versus frequency for different incident angles $\theta_{\text {inc }}$ between $0^{\circ}$ and $60^{\circ}$ has been simulated for transverse electric (TE) polarized waves. The absolute and relative deviations of the resonance frequencies can be obtained from Figure 4 . For the lower frequency band: $30 \mathrm{MHz}, 1.2 \%$ for $\theta_{\text {inc }}=45^{\circ}$ and $149 \mathrm{MHz}, 6 \%$ for $\theta_{\text {inc }}=$ $60^{\circ}$. For the upper frequency band: $20 \mathrm{MHz}, 0.3 \%$ for $\theta_{\text {inc }}$ $=45^{\circ}$ and $100 \mathrm{MHz}, 1.7 \%$ for $\theta_{\text {inc }}=60^{\circ}$. The AMC operation bandwidth is slightly reduced from $\theta_{\text {inc }}=45^{\circ}$. From these obtained results, it can be concluded that the presented AMC design is highly stable as its angular margin ranges from $0^{\circ}$ to $45^{\circ}$ for the lower frequency band and from $0^{\circ}$ to $60^{\circ}$ for the upper frequency band. The upper frequency band is more stable regarding oblique incidence.

\section{Characterization Results}

Laser micromachining is used to manufacture prototypes (see Figure 6) of the CPW-fed bow-tie antenna alone and combined with the AMC to be characterized in terms of return loss and radiation pattern for comparison.

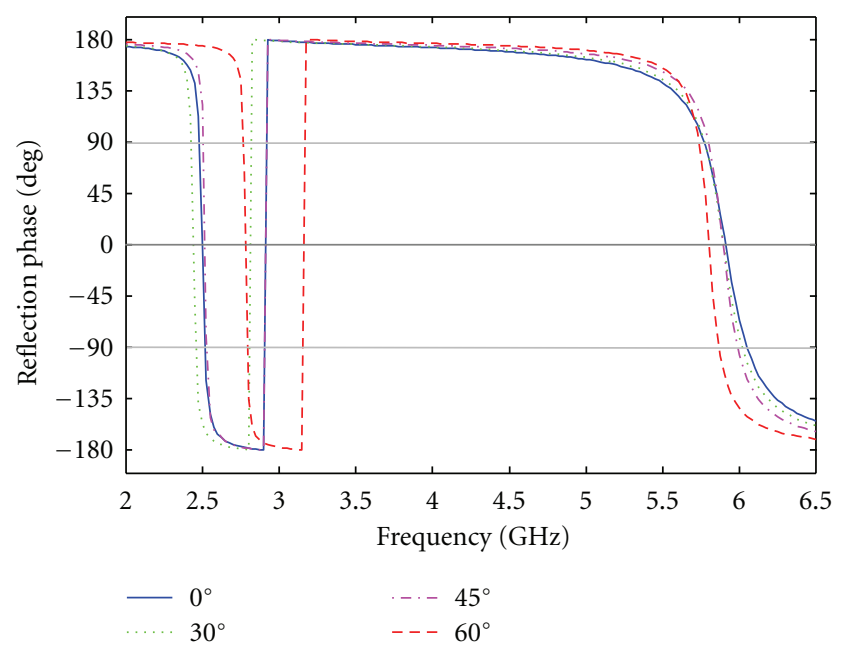

FIgure 4: Simulated reflection phase of the AMC surface for TE polarizations for different incident angles $\theta_{\text {inc }}=0^{\circ}, 30^{\circ}, 45^{\circ}$, and $60^{\circ}$.

4.1. Return Loss. The results of measured return loss for the manufactured prototypes are detailed in Figures 5 and 6 and Table 2.

The bow-tie antenna exhibits a measured operating bandwidth of $1.358 \mathrm{GHz}(23.89 \%)$, which is slightly wider than the $1.235 \mathrm{GHz}(21.66 \%)$ obtained by simulation due to the fact that the commercial MoM software considers infinite 
TABle 2: Prototypes comparison.

\begin{tabular}{|c|c|c|c|c|c|}
\hline \multirow{2}{*}{ CPW-antenna } & \multicolumn{3}{|c|}{ Frequencies $(\mathrm{GHz})$} & \multicolumn{2}{|c|}{ Bandwidth } \\
\hline & $f_{\text {Low }}$ & $\mathrm{fr}$ & $f_{\mathrm{Up}}$ & Total $(\mathrm{MHz})$ & $\%$ \\
\hline \multirow{2}{*}{ Bow-tie } & - & - & - & - & - \\
\hline & 5124 & 5683 & 6482 & 1358 & 23.89 \\
\hline \multirow{2}{*}{ Bow-tie-AMC } & 2160 & 2255 & 2315 & 155 & 6.87 \\
\hline & 5743 & 6137 & 6248 & 505 & 8.22 \\
\hline \multirow{2}{*}{ Bow-tie-AMC metallic plate } & 2056 & 2204 & 2285 & 229 & 10.39 \\
\hline & 5767 & 5914 & 6588 & 821 & 13.88 \\
\hline
\end{tabular}

TABLE 3: Measured gain, directivity, and radiation efficiency.

\begin{tabular}{|c|c|c|c|c|c|c|}
\hline \multirow{2}{*}{ CPW-antenna } & \multicolumn{3}{|c|}{$f=2.20 \mathrm{GHz}$} & \multicolumn{3}{|c|}{$f=5.80 \mathrm{GHz}$} \\
\hline & $G(\mathrm{~dB})$ & $D(\mathrm{~dB})$ & $\eta(\%)$ & $G(\mathrm{~dB})$ & $D(\mathrm{~dB})$ & $\eta(\%)$ \\
\hline Bow-tie & - & - & - & 2.2 & 5.4 & 48 \\
\hline Bow-tie-AMC & 3.1 & 6.5 & 46 & 2.4 & 5.9 & 45 \\
\hline Bow-tie-AMC metallic plate & 2.9 & 6.9 & 40 & 2.1 & 6.4 & 37 \\
\hline
\end{tabular}

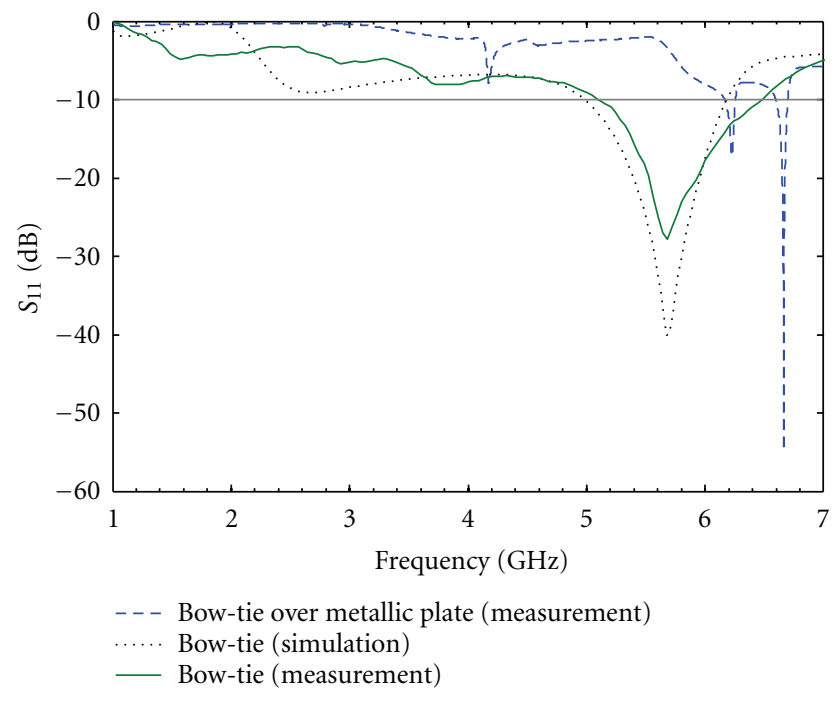

Figure 5: Bow-tie antenna's return loss.

extension for the dielectric substrate or even more likely to manufacturing tolerances.

When the bow-tie antenna is placed on the AMC, the antenna resonance frequency is shifted upwards, as the AMC resonance frequency is higher than the antenna one and in addition, it has higher quality factor. Also a new resonance frequency appears at $2.255 \mathrm{GHz}$ which makes the Bow-tieAMC combination proper for dual-band applications.

As it could be expected, when the bow-tie antenna alone is placed on a metallic plate the antenna resonance frequency has been shifted out of the $5.8 \mathrm{GHz}$ band leading to its total malfunctioning (see Figure 5). However, from Figure 6 and Table 2, the bow-tie-AMC combination exhibits proper dualband performance both alone and when placed on a metallic plate, even showing bandwidth enhancement on a metallic plate.

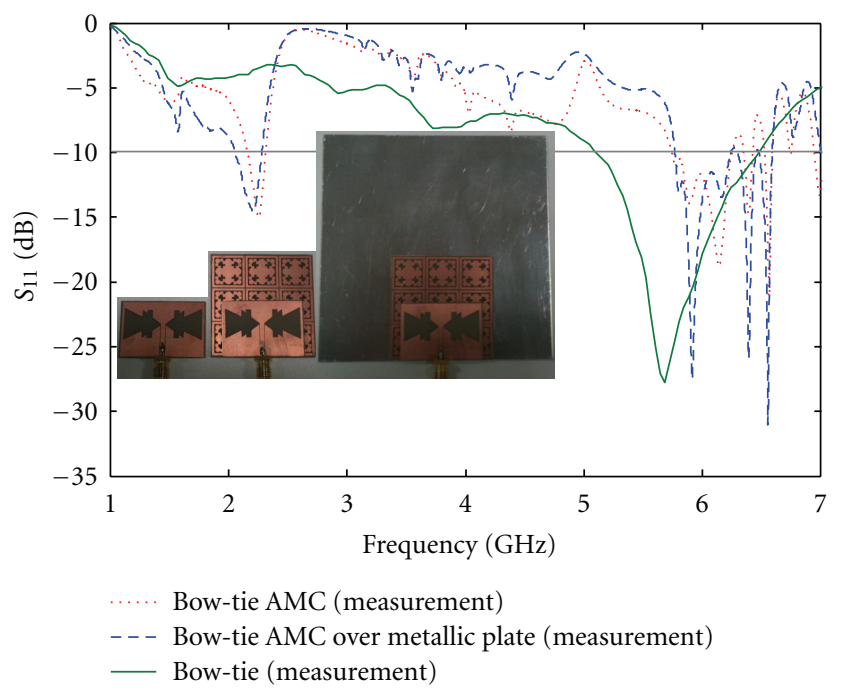

Figure 6: Measured input return loss for the prototypes: bow-tie, bow-tie-AMC, and bow-tie-AMC on a metallic plate.

4.2. Radiation Pattern. Measured radiation pattern cuts in the $E$ - and $H$-planes of the manufactured prototypes at 2.2 $\mathrm{GHz}$ (lower band) and at $5.8 \mathrm{GHz}$ (upper band) are, respectively, plotted in Figures 7 and 8. H-plane tends to be omnidirectional as it could be expected. The radiation pattern properties of the bow-tie-AMC for RFID application are still preserved even when it is placed on a metallic plate, as the AMC electromagnetically insulates the antenna from the metal and so the bow-tie-AMC currents distribution is not modified. From Figure 8, it can be observed how the AMC reduces the antenna backward radiation between 10 and $20 \mathrm{~dB}$.

The measurement set-up is shown in Figure 9. Table 3 shows the measured Gain, directivity, and radiation efficiency at $2.2 \mathrm{GHz}$ and $5.8 \mathrm{GHz}$ for the manufactured prototypes. 
E-plane $(Y Z) \phi=90^{\circ}$

90

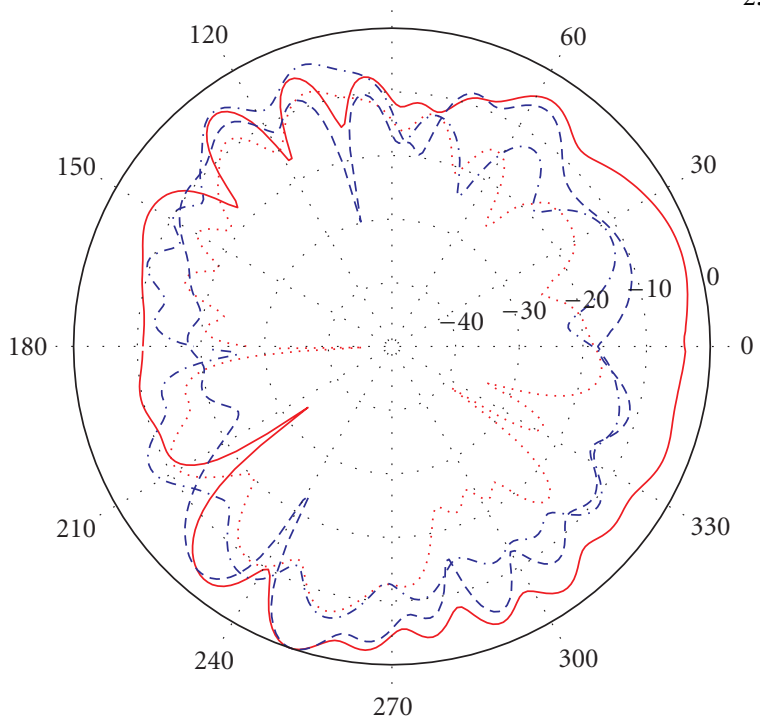

— Bow-tie-AMC, CP

..... Bow-tie-AMC, XP

--- Bow-tie-AMC over metallic plate, CP

...- Bow-tie-AMC over metallic plate, XP

(a)
$E$-plane $(X Z) \phi=0^{\circ}$

$2.2 \mathrm{GHz}$

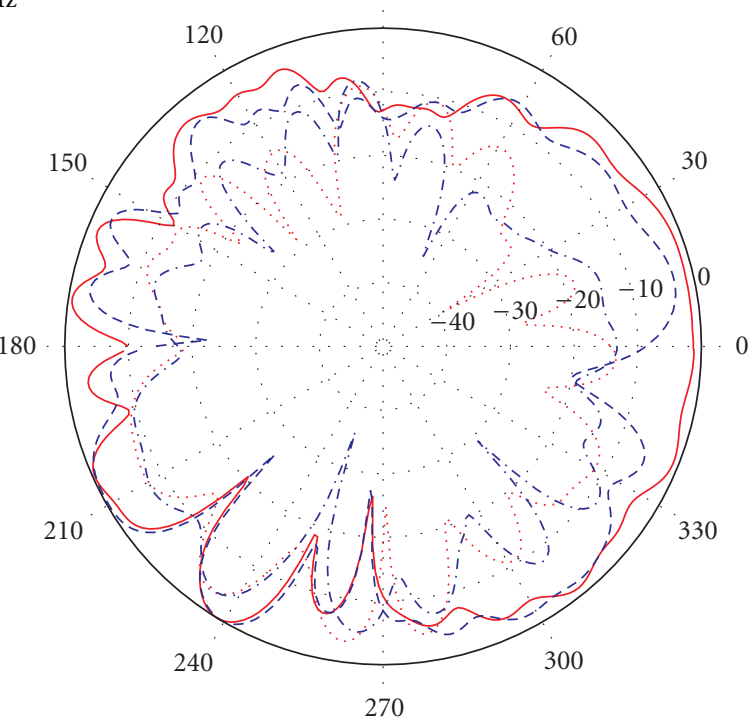

— Bow-tie-AMC, CP

.... Bow-tie-AMC, XP

- - - Bow-tie-AMC over metallic plate, $\mathrm{CP}$

-..- Bow-tie-AMC over metallic plate, XP

(b)

Figure 7: Measured radiation pattern (normalized, in dB) E-plane (a) and $H$-plane (b) at $2.2 \mathrm{GHz}$.
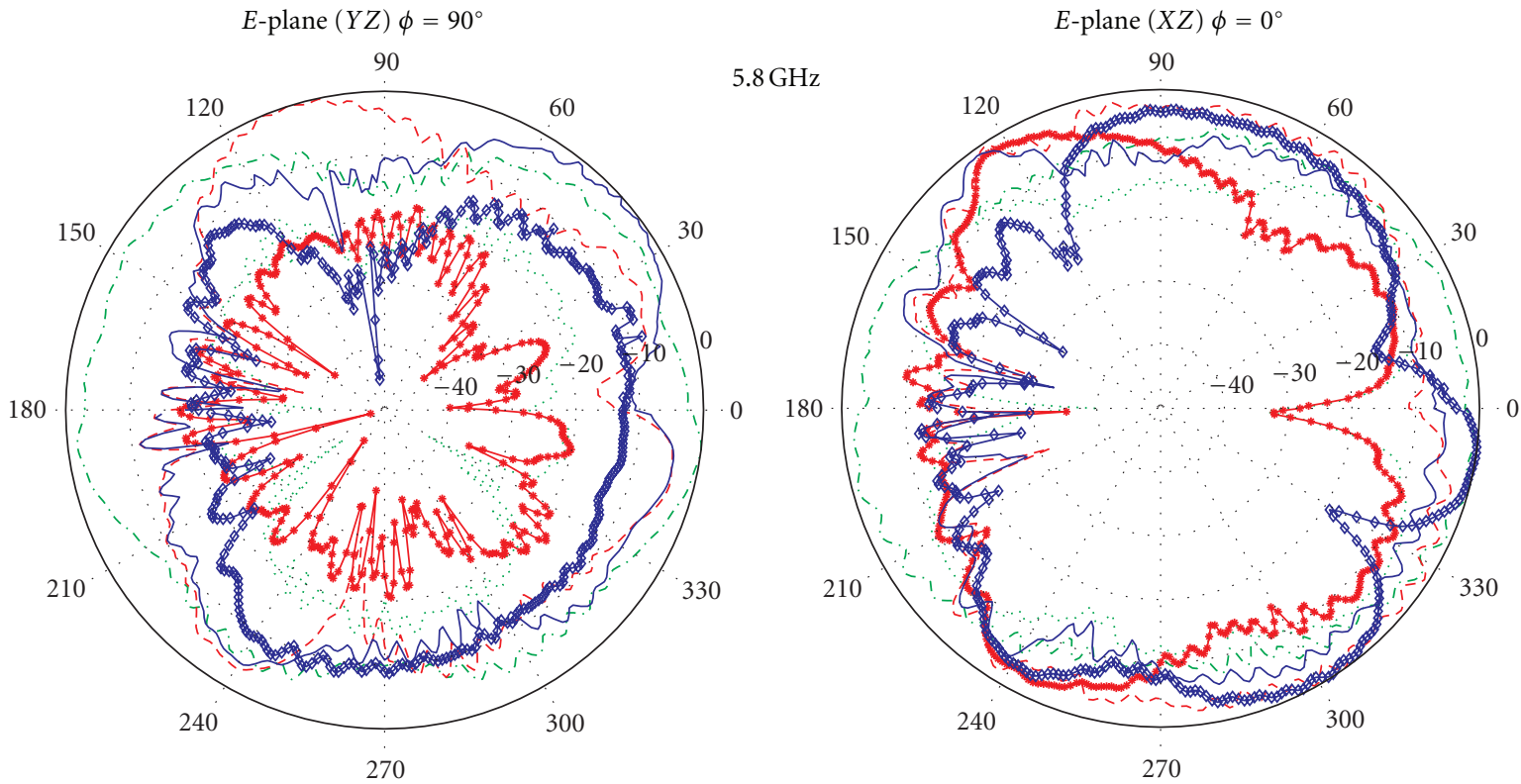

-. Bow-tie, CP Bow-tie, XP

- - - Bow-tie-AMC, CP

$\rightarrow$ Bow-tie-AMC, XP

- Bow-tie-AMC over metallic plate, $\mathrm{CP}$

$\rightarrow$ Bow-tie-AMC over metallic plate, XP

(a)

-.- Bow-tie, CP

..... Bow-tie, $\mathrm{XP}$

- - Bow-tie-AMC, CP

$\rightarrow$ Bow-tie-AMC, XP

- Bow-tie-AMC over metallic plate, $\mathrm{CP}$

$\rightarrow$ Bow-tie-AMC over metallic plate, XP

(b)

Figure 8: Measured radiation pattern (normalized, in dB) E-plane (a) and $H$-plane (b) at $5.8 \mathrm{GHz}$. 


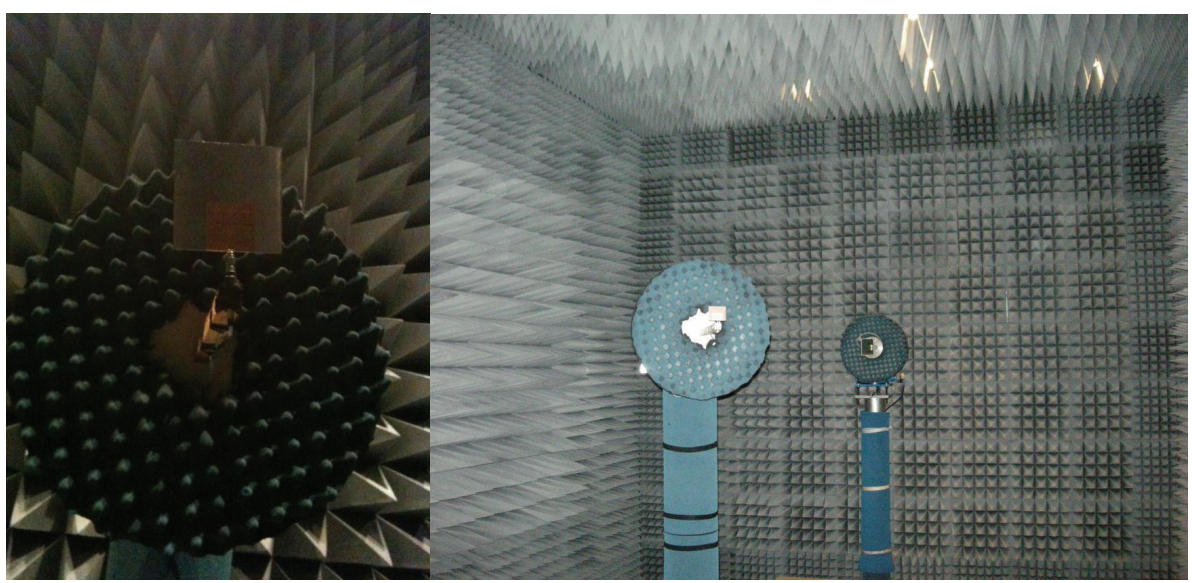

FIGURE 9: Measurement setup in anechoic chamber.

From the obtained results, it can be concluded that the bow-tie-AMC combination makes possible to obtain proper dual-band operation on metallic objects preserving the antenna gain around $3 \mathrm{~dB}$ for the lower band and $2.2 \mathrm{~dB}$ for the upper band. When the bow-tie-AMC combination is placed on a metallic object, is the radiation efficiency is slightly, reduced. However, it is remarkable that the measurements on metallic plate have been carried out placing the bow-tie-AMC combination on the edge of the plate, which can be considered the worst case. If the bow-tie-AMC combination were centered on the metallic plate, theoretically, a $6 \mathrm{~dB}$ improvement on gain with respect to bow-tie antenna alone should be obtained with slight variation on directivity, leading to radiation efficiency improvement.

\section{Conclusions}

Through a proper bow-tie-AMC combination, consisting of a CPW-fed double bow-tie antenna and a dual AMC, dual-band operation on metallic objects preserving antenna gain and with slight variation on radiation efficiency can be obtained. In addition, the antenna's backward radiation is reduced, which is a key point in wearable antennas and RFID tags usable with people.

A remarkable characteristic of the bow-tie-AMC combination is its compact size: $44.1 \mathrm{~mm}\left(\lambda_{0} / 3.1\right.$ at $\left.2.2 \mathrm{GHz}\right)$ and low thickness: $1.524 \mathrm{~mm}\left(\lambda_{0} / 90\right.$ at $\left.2.2 \mathrm{GHz}\right)$ its thicker part, which makes it proper for integration in dual-band wireless communication systems. The presented design could be used in RFID applications as tag antennas for both metallic and nonmetallic objects but it could be also used in other dualband RF systems in the SHF band.

\section{Acknowledgments}

This paper has been supported by the Ministerio de Ciencia e Innovación of Spain/FEDER under Projects TEC2011-24492/TEC (iScat) and CONSOLIDER-INGENIO CSD2008-00068 (TERASENSE), and by the Gobierno del Principado de Asturias (PCTI)/FEDER-FSE under Projects PC10-06 (FLEXANT).

\section{References}

[1] D. M. Dobkin and S. M. Weigand, "Environmental effects on RFID tag antennas," in Proceedings of the IEEE MTT-S International Microwave Symposium, pp. 135-138, Sunnyvale, Calif, USA, June 2005.

[2] R. H. Clarke, D. Twede, J. R. Tazelaar, and K. K. Boyer, "Radio frequency identification (RFID) performance: the effect of tag orientation and package contents," Packaging Technology and Science, vol. 19, no. 1, pp. 45-54, 2006.

[3] K. V. S. Rao, P. V. Nikitin, and S. F. Lam, "Antenna design for UHF RFID tags: a review and a practical application," IEEE Transactions on Antennas and Propagation, vol. 53, no. 12, pp. 3870-3876, 2005.

[4] P. Raumonen, L. Sydänheimo, L. Ukkonen, M. Keskilammi, and M. Kivikoski, "Folded dipole antenna near metal plate," in Proceedings of the IEEE International Antennas and Propagation Symposium and USNC/CNC/URSI North American Radio Science Meeting, pp. 848-851, June 2003.

[5] L. Ukkonen, L. Sydänheimo, and M. Kivikoski, "Effects of metallic plate size on the performance of microstrip patchtype tag antennas for passive RFID," IEEE Antennas and Wireless Propagation Letters, vol. 4, no. 1, pp. 410-413, 2005.

[6] S. Zhu and R. Langley, "Dual-band wearable textile antenna on an EBG substrate," IEEE Transactions on Antennas and Propagation, vol. 57, no. 4, pp. 926-935, 2009.

[7] M. Mantash, A. C. Tarot, S. Collardey, and K. Mahdjoubi, "Dual-band CPW-fed G-antenna using an EBG structure," in Proceedings of the 6th Loughborough Antennas and Propagation Conference (LAPC'10), pp. 453-456, Loughborough, UK, November 2010.

[8] P. Salonen, F. Yang, Y. Rahmat-Samii, and M. Kivikoski, "WEBGA—wearable electromagnetic band-gap antenna," in Proceedings of the IEEE Antennas and Propagation Society International Symposium, vol. 1, pp. 451-454, Monterrey, Calif, USA, June 2004.

[9] E. A. Soliman, S. Brebels, P. Delmotte, G. A. E. Vandenbosch, and E. Beyne, "Bow-tie slot antenna fed by CPW," Electronics Letters, vol. 35, no. 7, pp. 514-515, 1999.

[10] Y. L. Chen, C. L. Ruan, and L. Peng, "A novel ultra-wideband bow-tie slot antenna in wireless communication systems," Progress in Electromagnetics Research Letters, vol. 1, pp. 101108, 2008. 
[11] R. C. Hadarig, M. E. de Cos, Y. Álvarez, and F. Las-Heras, "Novel bow-tie-AMC combination for 5.8-GHz RFID tags usable with metallic objects," IEEE Antennas and Wireless Propagation Letters, vol. 9, pp. 1217-1220, 2010.

[12] M. Mantash, A. C. Tarot, S. Collardey, and K. Mahdjoubi, "Dual-band CPW-fed G-antenna using an EBG structure," in Proceedings of the 6th Loughborough Antennas and Propagation Conference (LAPC'10), pp. 453-456, Loughborough, UK, November 2010.

[13] E. Rajo-Iglesias, L. Inclán-Sánchez, and O. Quevedo-Teruel, "Back radiation reduction in patch antennas using planar soft surfaces," Progress in Electromagnetics Research Letters, vol. 6, pp. 123-130, 2009.

[14] ADS Momentun EM simulation tool, http://www.agilent .com/find/eesof.

[15] F. R. Yang, K. P. Ma, Y. Qian, and T. Itoh, "A uniplanar compact photonic-bandgap (UC-PBG) structure and its applications for microwave circuits," IEEE Transactions on Microwave Theory and Techniques, vol. 47, no. 8, pp. 1509-1514, 1999.

[16] D. Sievenpiper, L. Zhang, R. F. Jimenez Broas, N. G. Alexöpolous, and E. Yablonovitch, "High-impedance electromagnetic surfaces with a forbidden frequency band," IEEE Transactions on Microwave Theory and Techniques, vol. 47, no. 11, pp. 2059-2074, 1999.

[17] A. Monorchio, G. Manara, and L. Lanuzza, "Synthesis of artificial magnetic conductors by using multilayered frequency selective surfaces," IEEE Antennas and Wireless Propagation Letters, vol. 1, pp. 196-199, 2002.

[18] F. Yang and Y. Rahmat-Samii, Electromagnetic Band-Gap Structures in Antenna Engineering, The Cambridge RF and Microwave Engineering Series, Cambridge University Press, New York, NY, USA, 2008.

[19] M. E. de Cos, F. Las-Heras, and M. Franco, "Design of planar artificial magnetic conductor ground plane using frequencyselective surfaces for frequencies below $1 \mathrm{GHz}$," IEEE Antennas and Wireless Propagation Letters, vol. 8, pp. 951-954, 2009.

[20] M. E. de Cos, Y. Álvarez, and F. Las-Heras, "Planar artificial magnetic conductor: design and characterization setup in the RFID SHF band," Journal of Electromagnetic Waves and Applications, vol. 23, no. 11-12, pp. 1467-1478, 2009.

[21] D. J. Kern, D. H. Werner, A. Monorchio, L. Lanuzza, and M. J. Wilhelm, "The design synthesis of multiband artificial magnetic conductors using high impedance frequency selective surfaces," IEEE Transactions on Antennas and Propagation, vol. 53, no. 1 I, pp. 8-17, 2005.

[22] J. R. Sohn, K. Y. Kim, and H. S. Tae, "Comparative study on various artificial magnetic conductors for low-profile antenna," Progress in Electromagnetics Research, vol. 61, pp. 27-37, 2006.

[23] A. P. Feresidis, G. Goussetis, S. Wang, and J. C. Vardaxoglou, "Artificial magnetic conductor surfaces and their application to low-profile high-gain planar antennas," IEEE Transactions on Antennas and Propagation, vol. 53, no. 1 I, pp. 209-215, 2005.

[24] M. E. de Cos, Y. Álvarez, R. C. Hadarig, and F. Las-Heras, "Novel SHF-band uniplanar artificial magnetic conductor," IEEE Antennas and Wireless Propagation Letters, vol. 9, pp. 4447, 2010.

[25] Ansoft HFSS, From Ansoft Corporation, Four Station Square Suite 200, Pittsburgh, PA, 15219.

[26] C. R. Simovski, P. de Maagt, S. A. Tretyakov, M. Paquay, and A. A. Sochava, "Angular stabilisation of resonant frequency of artificial magnetic conductors for TE-incidence," Electronics Letters, vol. 40, no. 2, pp. 92-93, 2004. 

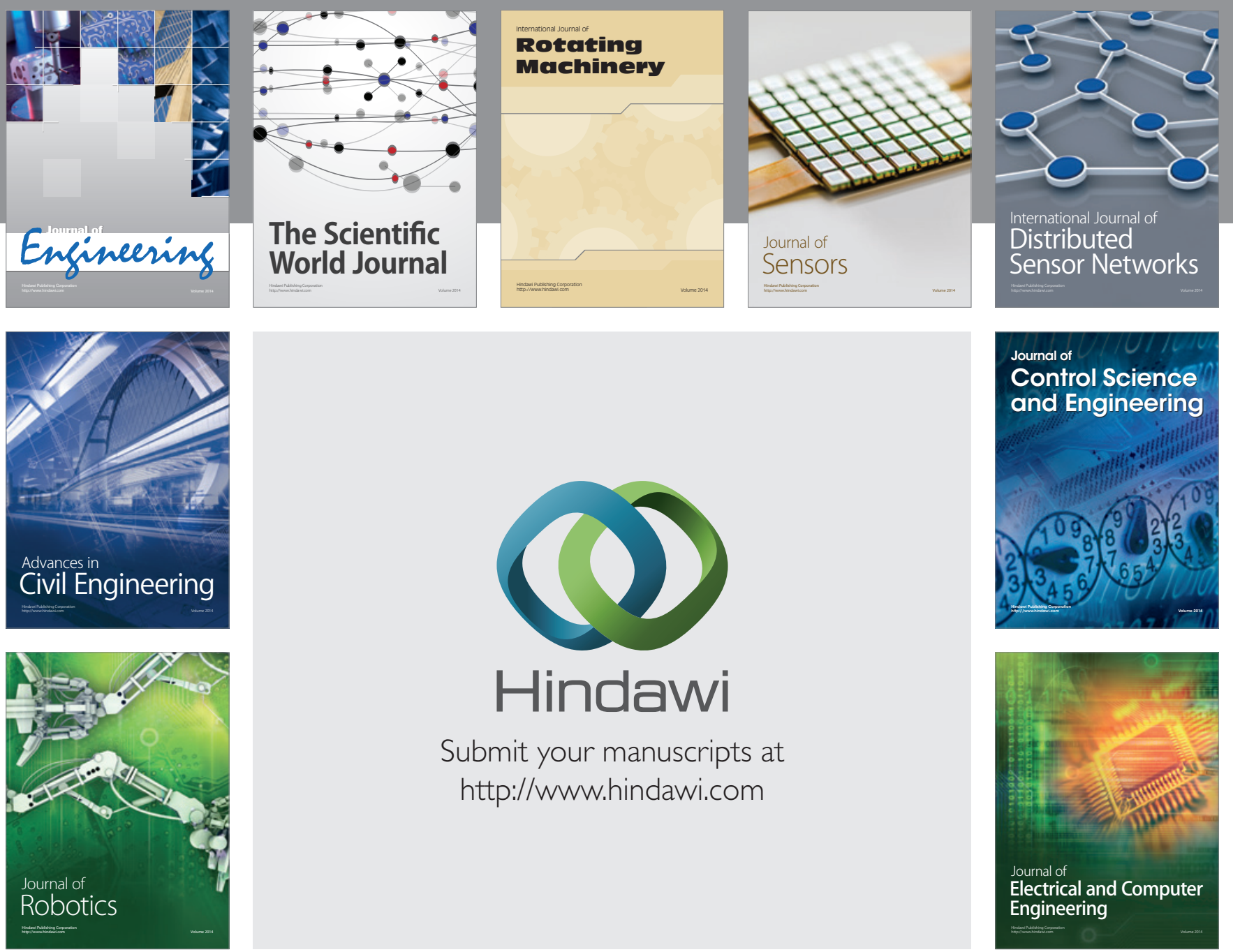

Submit your manuscripts at

http://www.hindawi.com
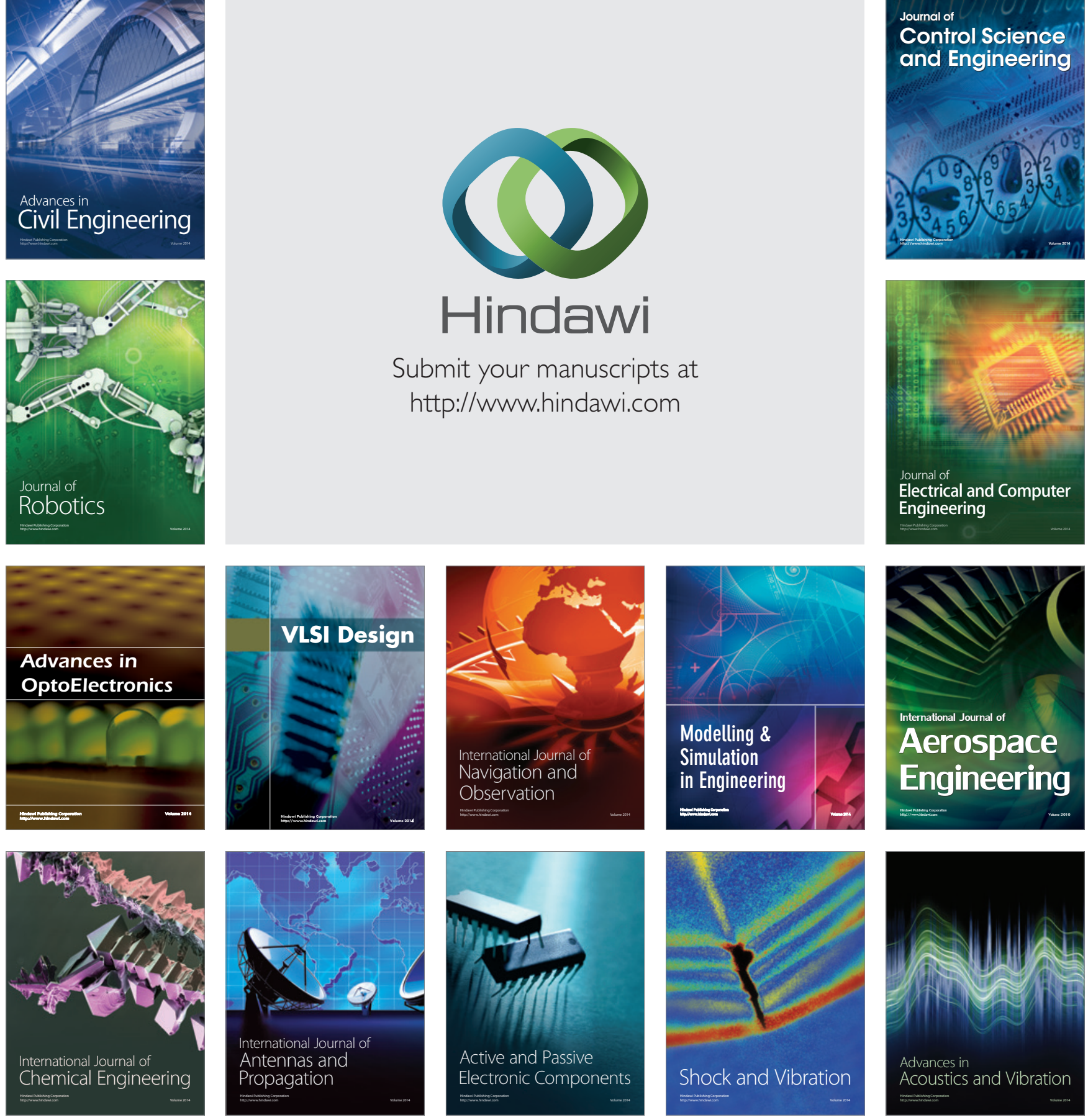